\title{
ANTROPOLOGIA E MISTICISMO: DIÁLOGOS COM UMA NATIVA NA REDE ${ }^{1}$
}

\author{
Francirosy Campos Barbosa Ferreira ${ }^{2} 3$
}

\begin{abstract}
Habibati ${ }^{4}$ : gostaria muito de falar com a senhora, Francirosy... o que acontece em seu blog merece um título "antropologia e misticismo", o que os turcos apresentam como Islam é algo caricato, deturpado e totalmente fora dos ensinamentos do Profeta, saws. Se há alguma tese em andamento, por favor, entre em contato comigo para certos ajustes, a menos que você prefira continuar na visão equivocada da religião - o que acontece com a maioria absoluta da sociedade (não haveria problema em relação ao mestrado/doutorado, pois os examinadores também ignoram em que consiste a religião). Comento com propriedade por haver morado na Turquia e na Síria... se quiser, entre em contato comigo: email...
\end{abstract}

Este artigo parte do "diálogo" que tive com uma muçulmana a respeito do meu blog http://francirosy.tumblr.com/ e do conteúdo que venho postando nele. O blog foi postado em uma comunidade de mulheres muçulmanas revertidas ${ }^{5}$ no Facebook, por outra muçulmana, que tinha por objetivo divulgar o trabalho que faço sobre as comunidades islâmicas. $\mathrm{O}$ exercício proposto neste texto é uma tentativa de reflexão sobre este diálogo tenso/denso entre pesquisadora e religiosa.

\footnotetext{
${ }^{1}$ Agradeço a Cornelia Eckert pelo convite e estimulo para escrever este artigo e Agradeço a Milton Bortoleto, pelas provocações certeiras e dicas que foram preciosas para escrita deste artigo.

${ }^{2}$ Universidade de São Paulo, Brasil.

${ }^{3}$ Antropóloga, Docente do Departamento de Psicologia da FFCLRP - USP. Pesquisadora do NAPEDRA - Núcleo de antropologia, performance e drama; pesquisadora do GRAVI - Grupo de antropologia visual; coordenadora do GRACIAS - Grupo de Antropologia em Contextos Islâmicos e Árabes;

E-mail: franci@ffclrp.usp.br.

${ }_{5}^{4} \mathrm{O}$ anonimato da minha interlocutora é proposital.

${ }^{5}$ Revertido trata-se de uma categoria nativa, para dizer que todo homem nasce muçulmano, portanto há um retorno à religião, quando este homem durante a vida se afasta do que os muçulmanos chamam de senda reta. (Cf. Ferreira, 2009b).
} 
ANTROPOLOGIA E MISTICISMO...

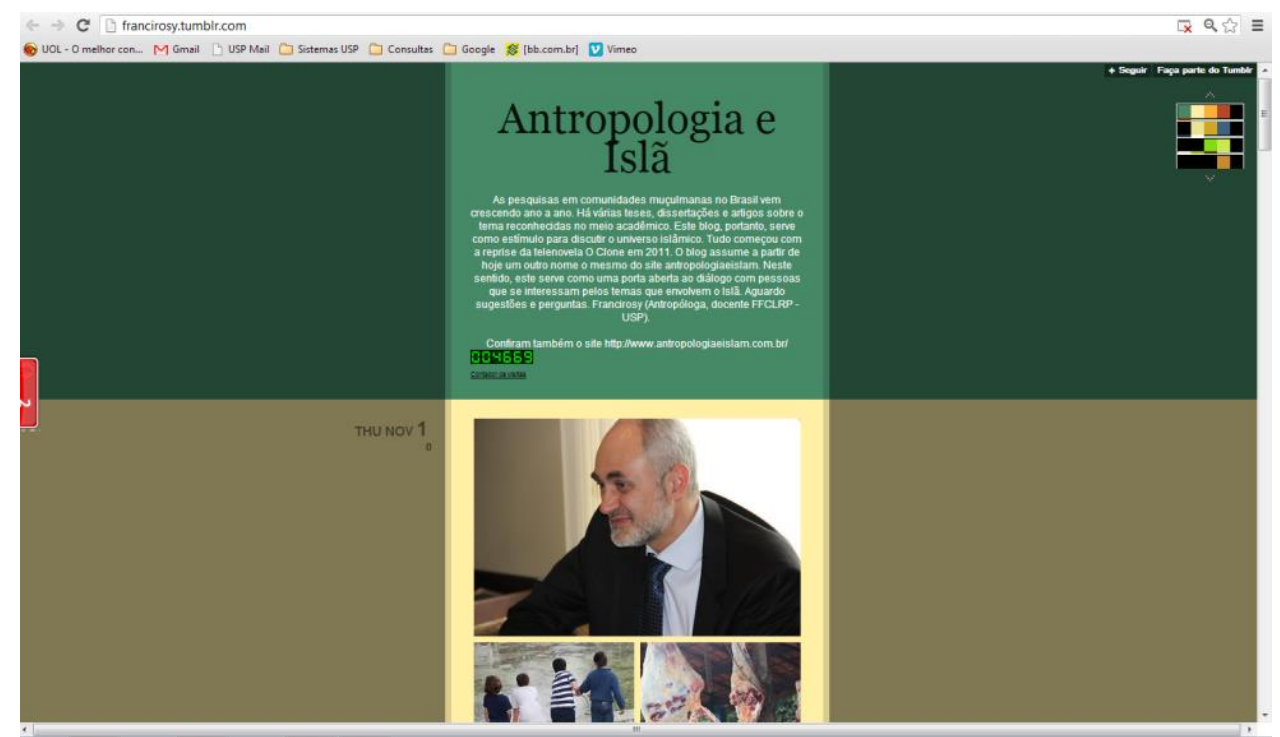

1. Blog Antropologia e Islã. ${ }^{6}$

$* * *$

A criação deste blog se deu em janeiro de 2011 com a finalidade de acompanhar a reprise da telenovela $O \mathrm{Clone}^{7}$ e, desta forma, analisar o núcleo muçulmano. Quando a reprise terminou resolvi permanecer com o blog e postar outros momentos de pesquisa relacionados ao Islã. Em julho de 2012 estive em Istambul e Konya e foram essas imagens vistas pela interlocutora em questão http://francirosy.tumblr.com/page/2 que desencadearam a nossa conversa no Facebook.

$* * *$

\footnotetext{
${ }_{7}^{6}$ Acesso em 27 de Novembro de 2012.

${ }^{7}$ Telenovela escrita pela autora Glória Perez de outubro de 2001 a julho de 2002. Escrevi um artigo sobre a reprise da telenovela, o qual está sendo avaliado por outra revista.
} 


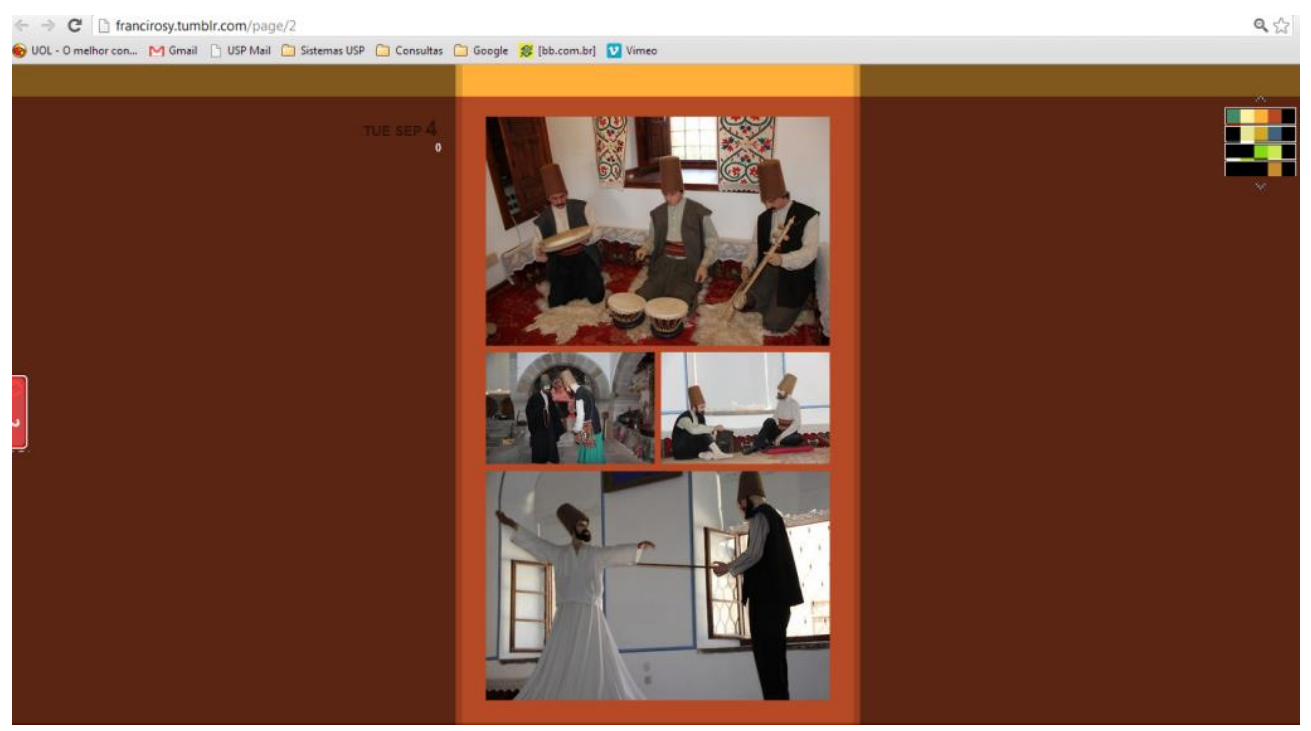

2. Blog Antropologia e Islã.

A internet é um meio de exposição que carrega em si benefícios e malefícios, e tanto antropólogos, como pesquisados, precisam relativizar as conversas que lá são (ex)postas. Os grupos que pesquisamos são ao mesmo tempo invisíveis e tangíveis. Estão em constante transformação, só o "distanciamento", em certos momentos, nos ajuda a compreender as nuances que são estabelecidos no terreno da pesquisa presencial e virtual. A observação de Devos e Vendana (2010) de que na produção de etnografias, a imagem não substitui nem facilita o esforço da descrição densa, e que o mesmo poderia dizer da hipermídia que traz a este campo outras perguntas, outras questões, nos faz perceber, que há sempre novos caminhos a serem trilhados e outras questões que mobilizam o campo a ser etnografado.

Quando iniciei minhas pesquisas com fotografias de comunidades muçulmanas em São Paulo, no final da década de 1990, meu interesse era produzir uma análise das imagens produzidas pelos muçulmanos, pela imprensa e por mim, entender como se constrói a imagem do outro com seus limites e potencialidades (Cf. Ferreira, 2001, 2002, 2004, 2009a). No doutorado a ênfase foi nas performances religiosas, festas e rituais que constituem o etos islâmico (Cf. 2007, 2009). Hoje venho trabalhando com antropologia da antropologia, olhando diretamente ao trabalho produzido por pesquisadoras de Islã e os modos como adentram em seus campos, etc. O produto desta pesquisa pode ser consultada no site antropologia e islam 
http://www.antropologiaeislam.com.br/. Ao passo que ao olhar para pesquisadoras, suas etnografias e metodologias, também, estou a olhar para minha prática, o meu fazer.

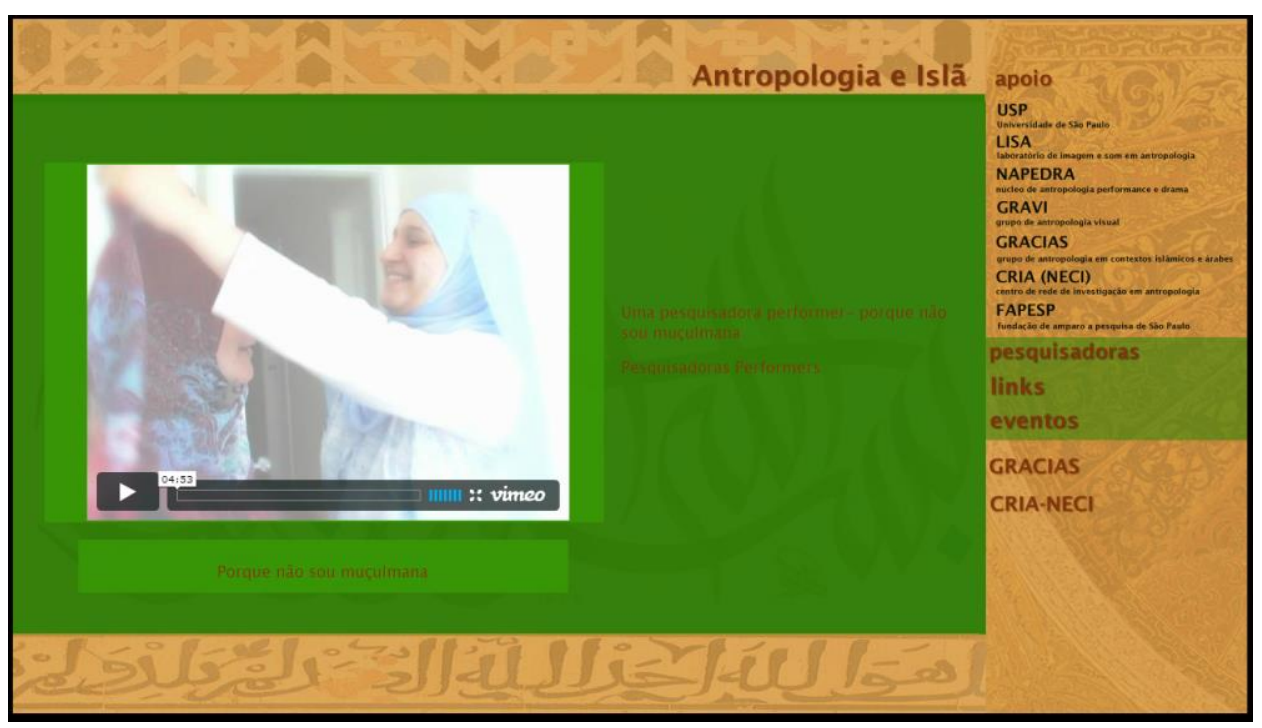

3. Site Antropologia e Islã. ${ }^{8}$

Os blogs, sites e outras interações virtuais vêm sendo objetos de reflexão nos últimos tempos. No 54\% ${ }^{\circ}$ Congresso Internacional dos Americanistas, em Viena, apresentei o texto "Construindo um website (...)" ". Nessa comunicação explorei dois objetivos: os dilemas e os desafios que o fazer etnográfico tem evidenciado na construção de um website, tendo como tema central as pesquisas produzidas por pesquisadoras de Islã e a discussão sobre como a Antropologia vem lidando com essas novas formas de produção de conhecimento.

Neste artigo destaco alguns dos trabalhos importantes para esta reflexão. Roger Chartier (1999) no qual destaca as diferenças entre o texto e o hipertexto mostrando como na passagem "do Leitor ao Navegador" a intertextualidade está presente na navegação. A tela, segundo o autor, assume uma grande importância numa leitura por camadas que substitui a leitura sequencial do livro, desta forma, ao selecionar

\footnotetext{
${ }^{8}$ Acesso em 28 de Novembro de 2012.

${ }^{9}$ Cf. Revista Pensata, v.2, n.1 - Dezembro de 2012, p.145-158.
} 
fragmentos promove outra leitura, cria outro texto, que pode a qualquer momento não existir mais, por isso, a necessidade de citar a data de consulta do mesmo.

Bernardo Lewgoy em artigo intitulado - A invenção da (ciber)cultura Virtualização, aura e práticas etnográficas pós-tradicionais no ciberespaço - sugere de modo muito inteligente que:

(...) as etnografias realizadas em ambientes de interação virtual, como MUDS, IRCS, Salas de bate papo, Orkut, Second Life, etc., mais do que outros usos da internet, colocam em questão o estatuto da etnografia, de um modo análogo à incorporação das sociedades complexas como objetos de estudo antropológico. Ao mesmo tempo em que uma aura é agora projetada sobre o trabalho de campo presencial (tornando aliados os velhos adversários que se batiam no debate estudo de sociedades simples $\mathrm{x}$ estudo de sociedades complexas) a etnografia virtual suscitou novas questões epistemológicas e ontológicas para a Antropologia.

(Bernardo Lewgoy, 2009: 189).

Como bem destacaram Eckert e Rocha (2008), a antropologia vem incorporando há tempos mapas, gráficos, fórmulas matemáticas, fotografia etc., como forma de registro e exposição dos dados de campo e não seria diferente com as "novas tecnologias" digitais e eletrônicas. Certa de que, ainda, caminhamos em um terreno "argiloso", quando se trata de pesquisar e analisar o virtual, pois, não estar "frente a frente" com os interlocutores pode parecer abstração demais, no entanto, são outras formas de se "(re)apresentar" no mundo,conforme estabeleceu Peirano: "Conciliar audiências reais e virtuais, imediatas e remotas, locais e internacionais,torna-se muitas vezes um exercício de malabarismo para determinar prioridades e hierarquias de problemas" (1992: 3). Hine considera importante o meio virtual como um lugar a ser etnografado, pois, faz parte do universo da cultura, do social:

Nós podemos sugerir, então, que uma troca metodológica, a requisição do contexto on-line como um site de campo etnográfico foi crucial no estabelecimento do status das comunicações de Internet como cultura. Enquanto experimentos psicológicos demonstraram sua opacidade, métodos etnográficos foram capazes de demonstrar sua riqueza cultural. É possível ir mais longe e sugerir que nosso conhecimento da Internet como um contexto cultural está intrinsecamente ligado com a aplicação da etnografia. $\mathrm{O}$ método e o fenômeno definem o outro em um relacionamento de mútua dependência. $\mathrm{O}$ contexto on-line é definido como um contexto cultural pela demonstração de que a etnografia pode ser aplicada a ele. Se nós podemos estar confiantes de que a etnografia pode ser aplicada com sucesso em contextos on-line então nós podemos ficar seguros de que estes são, realmente, contextos culturais, uma vez que a etnografia é um método para entender a cultura.

(Hine, 2005: 8)

Ainda precisamos aprender a lidar com a rapidez e fluidez do virtual, pois nesse meio estamos abertos a todo tipo de intervenção, observação, críticas e elogios. Se antes 
os "nativos" não liam as teses, artigos, hoje eles estão no Facebook e em outras redes sociais e acompanham o trabalho que vem sendo realizado com maior ou menor proximidade. Cada vez mais os objetos e produtos de nossas etnografias não são apenas textuais, são audiovisuais. Essas imagens, sons, não são apenas instrumentos metodológicos, são objetos de analise e produção, e podem promover ações, "podem fazer coisas" (Cf. Latour, 2012: 109).

Neste artigo, portanto, tenciono falar do modo como o diálogo entre eu e uma interlocutora na rede social, acabou "gerando" uma rede muito maior de atores que se interconectam. Busca-se neste artigo problematizar a possibilidade não só de levar o nativo a sério, mas de levar a pesquisadora a refletir sobre essa seriedade: a sua, a deles, as nossas.

\section{Hijab justo - provoca desconforto}

Fazendo uma analogia a saia justa ${ }^{10}$, o hijab ${ }^{11}$ justo, também pode provocar tensões. A discussão sobre trabalho de campo, nem sempre é algo tranquilo, sem tensões. É sempre um risco elaborado, supostamente controlado, que nos movimenta. Às vezes, explicar aos nossos interlocutores o que faz um antropólogo não é algo fácil, requer muitas habilidades e dissonâncias, e mais do que isto, explicar que não nos interessa versões "verdadeiras", "origem" de um determinado fenômeno etc. Mas sim, o significado atribuído pelos agentes.

Retomando a epígrafe inicial deste artigo chamo atenção para alguns elementos expostos pela interlocutora:

(...) o que acontece em seu blog merece um título "antropologia e misticismo ${ }^{12 ",}$ o que os turcos apresentam como Islam é algo caricato, deturpado e totalmente fora dos ensinamentos do Profeta, saws ${ }^{13}$.

\footnotetext{
${ }^{10}$ Recomendo a leitura da coletânea "Entre saias justas e jogos de cintura", livro organizado por Alinne Bonetti e Soraya Fleischer (2007) sobre dilemas de trabalho de campo de jovens antropólogas.

${ }^{11}$ Hijab é o lenço usado pelas mulheres.

12 Misticismo é um termo grego para designar o "oculto", o "não-conhecido". No mundo helênico a palavra mística se referia ao segredo dos rituais praticados pelos sacerdotes. Cf. (Silva Filho, 2012: 19)

${ }^{13}$ Salla Allahu alayhi wasallam: (SLAS) "Que a Paz e as bênçãos de Allah desçam sobre o Profeta".
} 


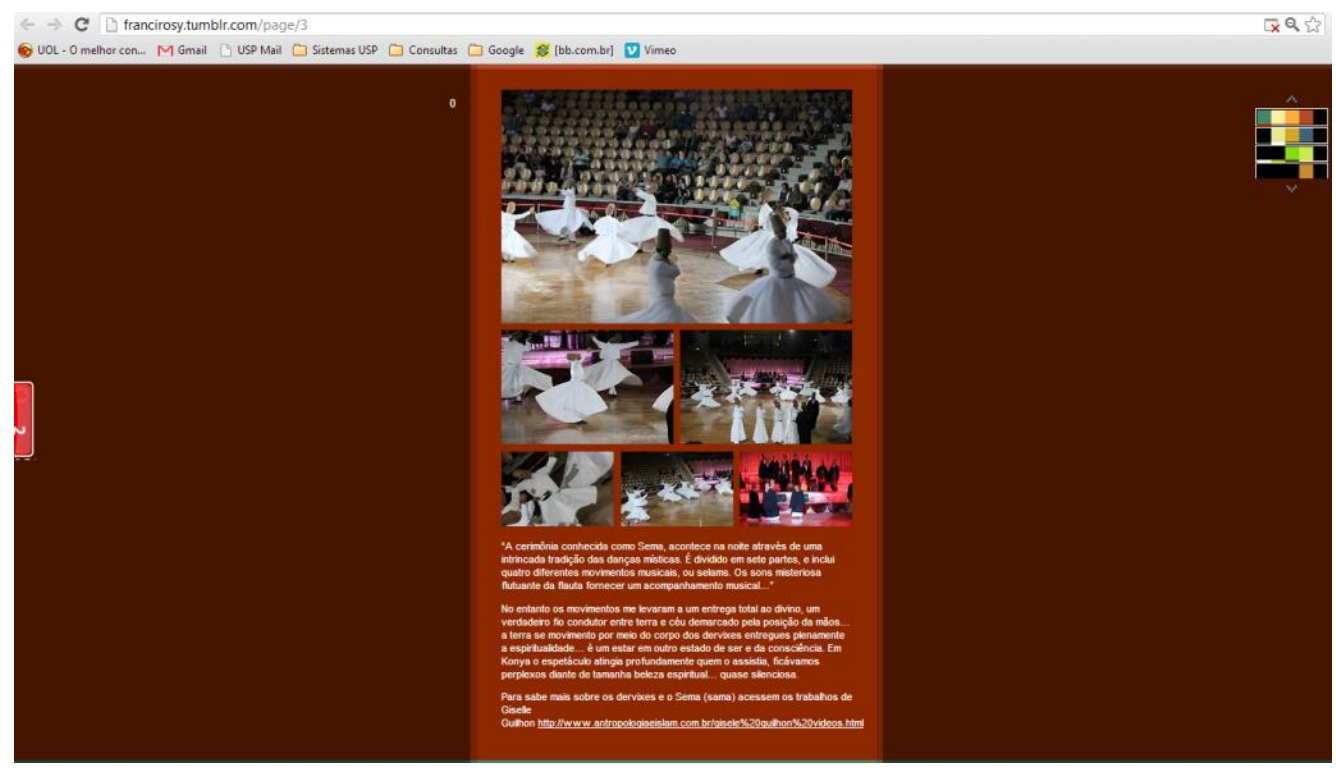

4. Blog Antropologia e Islã.

No momento da primeira leitura não consegui disfarçar a irritação com a alegação de que eu fazia "misticismo", pois a palavra soou como um descrédito ao trabalho que venho realizando. Depois, relendo com calma, percebi que a analogia se referia ao próprio Sufismo que é considerado a linha mística do Islã e passei então a ponderar sobre uma linha e outra (sunita e xiita).

O Sufis dentro do Islã são mal vistos, considerados hereges. O censo comum atribui ao Sufismo a ideia de misticismo, pois os fieis buscam o contato direto com Deus, muitas vezes, por meio de transe extáticos ou pelo Sama (audição), prática realizada pelos dervixes, que conecta dança e música, algo considerado haram (proibido) pela religião. Na academia encontram-se vários modos de definir o Sufismo, uns dirão que se refere a "adesão à cortesia espiritual ( $a d a b)$ ", outros que "é aniquilação do ego", "é uma prática de vida dedicada ao desenvolvimento das mais altas capacidades intuitivas" (Cf. Silva Filho, 2012).

De certo modo a interlocutora me colocou na situação exposta por Latour de que "os cientistas sociais tivessem que postular a existência, "lá fora", de um tipo real e de outros conjuntos falsos, obsoletos, insignificantes ou artificiais" (2012: 51). Eu "deveria saber" qual é o Islã correto e o obsoleto, falso. Aprendemos muito antes de Latour (5152) escrever, que "não há grupo relevante ao qual possa ser atribuído o poder de compor 
agregados sociais". O ponto de partida tem que ser as controvérsias já diria Latour, por isso insisti (mos) no diálogo...

Voltando ao texto dela:

Se há alguma tese em andamento, por favor, entre em contato comigo para certos ajustes, a menos que você prefira continuar na visão equivocada da religião - o que acontece com a maioria absoluta da sociedade (não haveria problema em relação ao mestrado/doutorado, pois os examinadores também ignoram em que consiste a religião). Comento com propriedade por haver morado na Turquia e na Síria... se quiser, entre em contato comigo: email...

(Grifo da autora)

Provocou desconforto os "certos ajustes", a visão equivocada, e a própria ideia de que os examinadores (acadêmicos) ignoram em que consiste a religião. Por alguns instantes esqueci que atores (nativos) tem sua própria metalinguagem elaborada e reflexiva (Cf. Latour, 2012: 53). Em resposta ao seu post disse que não precisava de auxilio, pois quando tenho alguma dúvida sobre a religião (prescritiva), ensinamentos, etc., pergunto a dois sheiks ${ }^{14}$ com qual mantenho contato há muito tempo.

Quem participa ativamente de redes sociais, sempre se vê em meio a algum tipo de polêmica, mas em se tratando de polêmica com o "nativo", isto pode ser um péssimo sinalizador e certamente traz estragos ao trabalho a ser realizado. Por isso, ao perceber que a conversa tomava rumos inesperados salvei o conteúdo, a fim de poder refletir com mais calma sobre este "diálogo" e assim discuti-lo com outros pesquisadores, e com o próprio sheik com quem tenho mais proximidade. Logo depois de ter salvado a conversa, percebi que a interlocutora em questão havia apagado os seus comentários. Tenho duas hipóteses para isto: 1- eu mesma havia comentado com a moderadora da página que se quisesse poderia apagar os meus posts, caso achasse que estava sendo desrespeitosa com a apresentação do blog (o que foi negado pela moderada); 2 - o segundo motivo, talvez, fosse o fato da minha relação com os sheiks citados, que são os nomes mais conhecidos dentro e fora da comunidade islâmica.

\footnotetext{
${ }^{14}$ Sobre o papel do Sheik em comunidades islâmicas conferir Ferreira (2007).
} 
$\mathrm{Na}$ conversa com o sheik, ele esclareceu que a música em determinadas situações desvia o fiel da sua relação com Deus e por isso, há restrições, mas que tudo depende do contexto, etc. Outro dado comentado foi sobre o grupo do qual esta senhora faz parte e vem dando trabalho às lideranças, pois sempre dialogam de forma inadequada com quem não é muçulmano, o que entendi que se tratava de uma postura sempre impositiva.

Em minha tese de doutorado (Ferreira, 2007) já expus os conflitos existentes internamente nas comunidades islâmicas em São Paulo. Um deles diz respeito à própria representatividade do sheik para comunidade. Embora, o sheik seja a pessoa com mais conhecimento religioso, pois para se tornar sheik é necessário anos de estudos em escolas especializadas, assim mesmo, reconhecer nele qualquer tipo de representatividade, muitas vezes, pode não acontecer por parte de alguns muçulmanos revertidos. Considerei também na tese que o sheik poderia ser ao mesmo tempo espelho e vidraça da comunidade, pois reflete um comportamento que deve ser seguido e mimetizado; e vidraça, porque sobre ele recaem todos os problemas da comunidade, sejam internos ou externos.

Ainda não satisfeita com a conversa com o Sheik, expus o ocorrido com o grupo de religião da qual faço parte e outros colegas (religioesnobrasilcontemporâneo) ${ }^{15}$ via email. Um dos colegas, Milton Bortoleto, que vem trabalhando com o tema Intolerância Religiosa - me fez a seguinte pergunta:

Por que levar até ele (sheik) as afirmações da recém reconvertida - seria o Sheik o detentor do que configura para você o que é um modelo de Islã e a recém reconvertida um erro estatístico do que configura o universo religioso do Islã no Brasil, em São Paulo? - e por que menosprezar o posicionamento dela ao afirmar que "ela era uma recém reconvertida, por isso fazia isso"?

A pergunta tal qual formulada me trouxe mais reflexões sobre o exercício etnográfico. Na verdade, o que não enxerguei à primeira vista foi o fato de estarmos ocupando espaços diferentes, nas palavras de Latour, poderíamos dizer sobre: "a natureza dos grupos: há varias formas contraditórias de se atribuir identidade aos atores. A natureza das ações: em cada curso da ação, toda uma variedade de agentes parece imiscuir-se e deslocar os objetivos originais" (:42). O que estava claro é que havia outros pontos na rede, que deveriam ser observados, além da pesquisadora e da nativa.

\footnotetext{
${ }^{15} \mathrm{O}$ grupo foi constituindo durante a preparação da disciplina "Religiões no Brasil Contemporâneo" que foi ministrada no segundo semestre de 2012 na USP pelo professor Vagner Gonçalves da Silva (USP) e por mim.
} 
Refazendo o percurso até aqui: uma muçulmana posta o meu blog em uma página do Facebook, uma outra muçulmana revertida comenta, questiona o conteúdo, eu respondo, apresento o texto ao sheik, que comenta que pessoas desse grupo vem dando trabalho, por fazerem interpretações equivocadas, um colega me interpela sobre a minha atitude frente a revertida e ao sheik. Cada ator descrito aqui faz parte de um agregado social, e por fazerem parte de "grupos" diferentes relativizam a sua maneira. Para existência de grupos há necessidade de "porta-vozes", afirma Latour, para que "falem pela" existência do grupo. Cada um dos mencionados aqui são porta-vozes, menos ou mais do seu próprio "grupo".

Sobre a questão da legitimação de quem deve falar em nome da comunidade, desenvolvi em minha tese de doutorado, pois todas as vezes que queria aprofundar um determinado assunto com um nativo, eles me diziam para conversar com o sheik, porque ele tinha mais conhecimento. No entanto, outros discursos apareciam em contraposição, uns diziam que o "sheik" não os representava, pois a religião era entre ele e Deus, sem intermediários. Uma fala do sheik no vídeo Vozes do Islã (Ferreira, 2007) é interessante para nominar essas diferenças. Ele diz que o "nascido muçulmano" considera mais a presença do sheik em sua vida, enquanto os revertidos tem maior dificuldade.

Ao perguntar a minha interlocutora quais seriam as incorreções. Ela responde:

\begin{abstract}
Habibati: 1- as fotos: homens com instrumentos musicais - música é haraam; 2 fotos dos dervices - a forma que eles praticavam o Islam e aquela dança é haraam, sendo considerado um culto pagão; 3- você cita uma estória de Rumi que define Muhammad, saws, como santo - ilícito!!!! Etc, etc... Olha, eu tenho evidencias para cada um dos detalhes ilícitos dentro do Islam que eu citei e que ainda não citei, mas não respondo mais por aqui. Se quiser conversar comigo, escreva-me no e-mail que eu passei e por lá te respondo com propriedade, enviando, para cada comentário ayaat do Qur'na e ahaadith... certo?
\end{abstract}

Vamos tentar compreender do item 3 ao 1. Para um melhor entendimento do leitor, cabe dizer, que o Islã está dividido entre sunitas e xiitas. Os primeiros são descendentes de Abu Bakr, que após a morte do profeta Muhammad, assume o posto como seu sucesso derivando daí a linha sunita, que hoje conhecemos com a maioria do grupo, entre eles a Arábia Saudita. A linha xiita por sua vez deriva de Ali, que era primo e genro do profeta, o que hoje representa o Irã. O sufismo, linha mística do islã, está 
presente nas duas linhas. A convivência entre sunitas e xiitas nem sempre é tranquila, mas é possível, no entanto, para muitos, os sufis são hereges, não seguem o islã correto, o verdadeiro. A dança a qual se refere é o Sama dança sufi, que significa audição, está em contato direto com Allah. Há alguns instrumentos proibidos no Islã, em geral instrumentos de cordas, mas não necessariamente isto tem um acordo geral. Habibita: você não sabe do que fala quando afirma que "nem toda música é ilícita"
- sim, toda música é ilícita: a música tem sido condenada fortemente no Qur'na e na
Sunnah. Na Surah Luqmaan, Allah (subhanahuwata'la) diz: "E, dentre os homens,
há quem compre falsas narrativas, para sem ciência, descaminhar os outros do
caminho de Allah..." (Qur'na 31: 6)
Sobre o comentário deste verso, IbnBaaz (rahimhullah) disse: "falsas narrativas"
refere-se à música e coisas relacionadas com ela".

(DurrulManthoor vol.5, p.307)

Na Surah Al-Isra, Allah (subhanahuwata'la) diz: "E provoca/seduz, com a tua voz, aqueles que puderes, dentre eles; aturde-os com a tua cavalaria e infantaria; associate a eles nos bens e nos filhos, e faze-lhes promessas! Qual! Satanás nada lhes promete, além de quimeras".

(Qur'na 17: 64)

Importante destacar que o fato da música ser proibida, não significa que os muçulmanos não a ouçam. O discurso religioso não se aplica ao cotidiano das comunidades que conheci em São Paulo, todas sem exceção tocavam música em seus encontros, festas. Durante o meu mestrado, participei de várias festas de mulheres, e sempre havia música e dança, assim como festas coletivas em uma das mesquitas em São Paulo.

As músicas permitidas são anasheed, são músicas cantadas em geral por voz masculina com instrumento de percussão. Há restrição também à voz feminina, considerada como aquela que altera os sentidos. No Islã tudo que altera os sentidos, que provoca mudança de atenção que não seja Allah é considerado ilícito. No trabalho de Tomassi (2011) sobre Hip Hop e Islã é possível considerar as aproximações e distanciamentos entre música e o movimento. A autora destaca alguns dos discursos sobre essas aproximações de membros do Hip Hop e Islã. Há pessoas na comunidade que desaprovam, outras que não veem problema.

Habibita: Ok, mas minha birra toda é que uma pessoa que é uma estudiosa (ou seja, uma formadora de opinião) intitula um website com o nome de uma religião e coloca um conteúdo que é ILÍCITO nesta religião... entende minha indignação, SIS? Um muslim não pode se calar ou cruzar os braços quando vê a religião de Allah, swt, sendo transmitida de forma equivocada... 
Ao reler esta passagem lembrei do questionamento feito por Viveiros de Castro (2002):

O que se passa quando o discurso do nativo funciona, dentro do discurso do antropólogo, de modo a produzir reciprocamente um efeito de conhecimento sobre esse discurso? Quando a forma intrínseca à matéria do primeiro modifica a matéria implícita na forma do segundo?

(Viveiros de Castro, 2002: 115)

O que fica deste diálogo é que detemos um determinado conhecimento, tal qual o sujeito pesquisado. Estamos diante da produção de um conhecimento. Forma de interpretação do seu próprio universo, concorde ou não com ele, é uma forma reflexiva de justificar de que lugar se está falando.

Como afirma Latour os "porta-vozes" estão sempre em ação, justificando a existência do grupo, invocando regras e precedentes - e, opondo uma definição às demais (:55).

\section{Considerações Finais: reiventando culturas e redes}

Não se teve a pretensão de encerrar por completo a discussão sobre os diálogos em campo, mas sim, trazer alguns elementos que pudessem elucidar tal dinâmica e modos de percepção que advém de diálogos virtuais. Roy Wagner afirma que:

\footnotetext{
um pesquisador deve ser tão imparcial quanto possível, na medida que esteja consciente dos seus pressupostos; mas frequentemente assumimos os pressupostos mais básicos de nossa cultura como tão certos que nem nos apercebemos deles.
}

(Roy Wagner, 2009: 39)

Talvez, esta afirmação ajude a refletir sobre o meu lugar no "diálogo". Ser contestado não é algo que avaliamos no momento como algo positivo, há certas nuances que são expostas do nosso trabalho que queremos deixar em repouso e não em evidencia e quase acionamos a nossa cultura que nem mesmo percebemos.

A ideia de cultura, como afirma Wagner, nos deixa em pé de igualdade com os nossos objetos de estudo. O sujeito tem sua cultura, que nós antropólogos experienciamos a nossa maneira por meio dos nossos próprios significados. De certo modo, isto nos faz concordar com o autor, que o antropólogo "inventa" a cultura que está estudando, não no sentido de livre fantasia, mas sim, de uma construção objetiva por meio da observação e aprendizado sobre a cultura do outro. 
O que pretendi neste (con)texto foi fazer exatamente o que não consegui quando dialogava pelo Facebook a de que pesquisador e pesquisados reinventam a cultura a qual fazem parte para que esta se torne "visível" no diálogo. O blog neste diálogo foi o objeto que contribuiu para rastrear as conexões sociais entre pesquisadora, nativa, sheik, grupo de pesquisa. As narrativas produzidas por ele, que na verdade são também produzidas por mim, ao passo que é a pesquisadora que seleciona o que postar, gera interpretações diversas. A percepção do social perpassa esses pontos, isto não significa, como alerta Latour (2012), obter simetria entre humanos e não-humanos (blog), e sim, considerar que há agência nos não-humanos, que nos permitem compreender ainda mais o humano.

\section{Referências}

BONETTI, Alinne; FLEISCHER, Soraya. Entre saias justas e jogos de cintura. Florianópolis: Editora Mulheres, 2007.

CHARTIER, Roger. A aventura do livro: do leitor ao navegador; conversações com Jean Lebrun. São Paulo: UNESP/IMESP, 1999.

DEVOS, R; VEDANA, V. Do audiovisual à hipermídia. Antropologia em primeira mão. Florianópolis: UFSC, 2010.

ECKERT, C.; ROCHA, Ana Luiza C. "A natureza da representação etnográfica e o conhecimento antropológico na WEB”. In: Iluminuras, v.7, n.16. Porto Alegre: BIEV/ UFRGS, 2006.

FERREIRA, Francirosy C. B. Imagem oculta - reflexões sobre a relação dos muçulmanos com as imagens fotográficas. 2001. 156f. Dissertação de Mestrado (Antropologia Social) - FFLCH, Universidade de São Paulo, São Paulo, 2001. " "A Linguagem fotográfica no Islã". In: Revista Travessia - revista do migrante, Ano XV, n.42. São Paulo: CEM, 2002. p. 22-28.

. "Cavalo de bronze: caligrafia e palavra". In: BARBOSA, Andréa et al (Orgs.). Escrituras da Imagem. São Paulo: EDUSP, 2004. p. 121-131. . “A imagem do Profeta - Proibir por quê?". In: Cadernos de Antropologia e Imagem, v.22. Rio de Janeiro: UERJ, 2006. p. 95-111.

Entre Arabescos, luas e tâmaras: performances islâmicas em São Paulo (tese de doutorado). São Paulo: FFLCH - USP, 2007.

"Abelhas, aranhas e pássaros: imagens islâmicas em movimento". In: BARBOSA, A. et al. Imagem-conhecimento: antropologia, cinema e outros diálogos. São Paulo: Papirus, 2009a.

."Redes Islâmicas em São Paulo: "Nascidos muçulmanos" e "revertidos"”. In.

Revista Litteris - Dossiê Estudos Árabes \& Islâmicos. Niterói: LEiFEn/ UFF, 2009b.

Disponível em:

http://antropologiasocial.com.br/wpcontent/uploads/2010/10/redesislamicasemsaopaulo. pdf. Acesso em: 30 de novembro, 2012.

. "Construindo um website - dilemas e desafios deste fazer etnográfico 
com pesquisadoras de comunidades muçulmanas". In: Revista Pensata, v.2, n.1. São Paulo: Unifesp, 2012. p.145-158.

HINE, Christine. "Virtual Methods and the Sociology of Cyber-Social-Scientific Knowledge". In: HINE, Christine (Org.).Virtual Methods. Issues in Social Research on the Internet. Oxford: Berg, 2005.

LATOUR, Bruno. Reagregando o social: uma introdução à teoria do Ator-Rede. Salvador: ED USC, 2012.

LEWGOY, Bernardo. "A invenção da (ciber)cultura: Virtualização, aura e práticas etnográficas pós-tradicionais no ciberespaço". In: Civitas, v.9, n.2. Porto Alegre: ediPUCRS, 2009. p. 185-196.

PEIRANO, Mariza G.S. “A favor da etnografia”. In: Série Antropologia, 130. Brasília: UnB, 1992. p.2-21.

SILVA FILHO, Mario A. A mística islâmica em Terrae Brasilis: o Sufismo e as Ordens Sufis em São Paulo. 2012. Dissertação (Mestrado em Ciências da Religião). PUC, São Paulo, 2012.

TOMASSI, Bianca. Assalamu Aleikum favela: a performance islâmica no movimento Hip Hop das periferias do ABCD e de São Paulo. Dissertação de Mestrado em Artes, Unicamp, Campinas, 2011.

WAGNER, Roy. A invenção da cultura. São Paulo: Cosac Naify, Portátil 16, 2009.

VIVEIROS DE CASTRO, Eduardo. "O Nativo relativo". In: Revista Mana. Rio de Janeiro: UFRJ, 2002.

\section{Filmografia}

FERREIRA, Francirosy, C. B. VOZES DO ISLÃ. Dirigido por Francirosy C.B.Ferreira. São Paulo: LISA, 2007, 25' NTSC, cor. 